\title{
AVALIAÇÃO DA MATURAÇÃO DOS FRUTOS DE LINHAGENS DAS CULTIVARES CATUAII AMARELO E CATUAÍ VERMELHO (Coffea arabica L.) PLANTADAS INDIVIDUALMENTE E EM COMBINAÇÕES ${ }^{1}$
}

\author{
Fruit ripening evaluations of Catuai Amarelo and Vermelho (Coffea arabica L.) \\ lineages of coffee cultivar, planted isolated and in combinations
}

\author{
Ângela Maria Nogueira ${ }^{2}$, Samuel Pereira de Carvalho ${ }^{3}$, Gabriel Ferreira Bartholo ${ }^{4}$, \\ Antônio Nazareno Guimarães Mendes ${ }^{3}$
}

\begin{abstract}
RESUMO
Instalou-se este experimento na Fazenda Experimental da EPAMIG em São Sebastião do Paraíso, MG, com o objetivo de avaliar as percentagens de frutos chochos e maturação de linhagens das cultivares Catuaí Vermelho (IAC 44, IAC 81 e IAC 99) e Catuaí Amarelo (IAC 47, IAC 62 e IAC 86), no período de 1994 a 1999, plantadas isoladas e em diferentes combinações. O experimento foi instalado obedecendo ao delineamento experimental de blocos ao acaso, com três repetições, parcelas constituídas de seis covas, com uma planta em cada uma adotando o sistema de manejo usualmente empregado na região, no espaçamento de 3,50 m entre linhas x 1,00 m entre covas. As linhagens foram agrupadas por cultivar plantadas isoladas e em multilinhas nas proporções de 33\% e 50\%. As análises estatísticas foram realizadas considerando seis características avaliadas individualmente, em parcelas subdivididas no tempo. Na análise estatística utilizou-se o teste de Duncan para comparação de médias. Pelos resultados, verificou-se que não houve diferenças significativas dos sistemas de plantio, isolado ou em combinações, sobre os diferentes estádios de maturação dos frutos.
\end{abstract}

Termos para indexação: café, maturação de frutos, Coffea arabica, misturas, isoladas.

\section{ABSTRACT}

The experiment conducted in EPAMIG's experimental station at São Sebastião do Paraíso, MG, to evaluate percentage of empty fruits and fruit ripening, of Catuaí Vermelho (IAC 44, IAC 81, and IAC 99) and Catuai Amarelo (IAC 47, IAC 62, and IAC 86), all Catuai lineages, from 1994 to 1999, planted isolated and in different combinations. A randomized block design was used, with 3 replications and 14 lineages combination as treatment, each plot with six plants, spaced 3.5 by $1.0 \mathrm{~m}$, respectively among interrows and lines. Lineages cultivars were grouped and planted isolated and in multi-lines at proposition of $33 \%$ and 50\%. Six characteristics were evaluated, and averages compared by Duncan test. There were no differences in planting systems over the fruit maturation stages and empty fruits.

Index terms: Coffee, fruit ripening, Coffea arabica, multi-lines, isolated.

(Recebido para publicação em 08 de abril de 2003 e aprovado em 15 de julho de 2004)

\section{INTRODUÇÃO}

O problema crucial das cultivares de cafeeiro, Catuaí Amarelo e Catuaí Vermelho, diz respeito, principalmente, à uniformidade de maturação dos frutos, devido a característica de florescimento, que em condições normais é em torno de cinco a seis, ou seja, maior que em outras cultivares, como por exemplo Mundo Novo, que é, em média, três floradas. Essa irregularidade no florescimento demonstra um grande diferencial nos estádios de maturação dos frutos, acarretando, dessa forma, uma heterogeneidade acen- tuada e, como conseqüência reflexos na qualidade do produto final.

Durante o crescimento dos frutos, várias fases são observadas e desenvolvidas de acordo com as épocas dos florescimentos. Após o estabelecimento da frutificação, verifica-se um período em que o crescimento dos frutos é desprezível; segue-se um período de crescimento rápido, até o fruto verde atingir seu tamanho final (metade do tamanho do fruto maduro). Nesse ponto o crescimento cessa por um longo período até o início da maturação, quando esse se reinicia e o fruto aumenta rapidamente de tamanho (WORMER, 1964; CANNELL, 1971).

1. Artigo extraído da Tese de Doutorado apresentada à Universidade Federal de Lavras/UFLA.

2. Doutoranda em Agronomia/Fitotecnia - Departamento de Agricultura/UFLA - Caixa Postal 3037 - 37.200-000 - Lavras - MG.

3. Professor Adjunto Departamento Agricultura/UFLA.

4. Pesquisador da EPAMIG. 
O fruto no estádio verde (chumbinho) compreende a fase inicial do seu desenvolvimento, que tem duração aproximada de seis semanas e é o período sem crescimento visível. A fase de expansão rápida do fruto ocorre ao final dessa, quando o endocarpo (pergaminho) endurece.

Desde a antese até o fruto verde chegar ao seu tamanho máximo, decorre um período de 4-6 meses, e o período de maturação toma dois meses ou mais, dependendo das condições ecológicas e da cultivar (SONDAHL e SHARP, 1979). O fruto no estádio verde-cana corresponde ao período intermediário entre o verde e o cereja, compreendendo as fases de formação do endosperma. A formação do endosperma ocorre durante a parte final da fase de expansão, com endosperma leitoso e endurecimento, que continua até antes da maturação (granação).

O fruto no estádio cereja compreende o período no qual os constituintes químicos atingem teores que conferem características peculiares da maturação completa, conduzindo o fruto ao ponto ideal de colheita, segundo Carvalho e Chalfoun (2000).

No estádio passa, após o amadurecimento total (café cereja), os frutos entram em um período em que o catabolismo predomina sobre o anabolismo, iniciando-se a fase de senescência dos frutos. Nessa fase, há fermentações com produções de álcoois e ácidos indesejáveis, ruptura da estrutura da parede celular por modificações nas pectinas, celuloses e hemiceluloses, escurecimento da casca e polpa, devido a oxidações de compostos fenólicos e pigmentos, e a qualidade do café tende a decrescer acentuadamente (CARVALHO e CHALFOUN, 2000).

O estádio seco é a fase final de secagem, representada por frutos contendo $11-12 \%$ de umidade, considerada ideal para o armazenamento dos frutos na forma integral ou após o beneficiamento (CARVALHO e CHALFOUN, 2000).

Dentre as linhagens superiores dessas cultivares, existem algumas com melhor desempenho em relação à característica de uniformidade de maturação; entretanto, não possibilitam atingir uma percentagem aceitável de frutos maduros no ponto ótimo de colheita, que é preconizado entre 80 a $85 \%$ de frutos no estádio cereja.

Neste trabalho, o objetivou-se verificar se multilinhas podem melhorar as características relacionadas à maturação de linhagens das cultivares de Catuaí Vermelho e Catuaí Amarelo, plantadas isoladas e em diferentes combinações.

\section{MATERIAL E MÉTODOS}

O experimento foi instalado em um Latossolo Vermelho distroférrico (LVd), na Fazenda Experimental de EPAMIG, em São Sebastião do Paraíso, MG, numa altitude de $890 \mathrm{~m}$, latitude $20^{\circ} 55^{\prime} \mathrm{S}$ e longitude $46^{\circ} 55^{\prime} \mathrm{W}$, com precipitação pluvial média de 1470 mm distribuídas de outubro a abril, e temperatura média anual de $20,8^{\circ} \mathrm{C}$.

$\mathrm{O}$ material estudado compreende três linhagens da cultivar Catuaí Vermelho; IAC 44, IAC 81 e IAC 99, e três da cultivar Catuaí Amarelo, IAC 47, IAC 62 e IAC 86. As linhagens foram agrupadas por cultivar e plantadas isoladas e em misturas de mudas nas proporções de 50\% e 33\% respectivamente.

Os tratamentos foram os seguintes: $\mathrm{T}_{1}=$ Catuaí Vermelho IAC 44; $\mathrm{T}_{2}=$ Catuaí Vermelho IAC 81; $\mathrm{T}_{3}=$ Catuaí Vermelho IAC 99; $\mathrm{T}_{4}=$ IAC $44+$ IAC 81; $\mathrm{T}_{5}=$ IAC $44+$ IAC 99; $\mathrm{T}_{6}=$ IAC $81+$ IAC 99; $\mathrm{T}_{7}=$ IAC $44+$ IAC $81+$ IAC 99; $\mathrm{T}_{8}=$ Catuaí Amarelo IAC 47; $\mathrm{T}_{9}=$ Catuaí Amarelo IAC 62; $\mathrm{T}_{10}=$ Catuaí Amarelo IAC 86; $\mathrm{T}_{11}=$ IAC $47+$ IAC 62; $\mathrm{T}_{12}=$ IAC $47+$ IAC $86 ; \mathrm{T}_{13}=$ IAC 62 $+\mathrm{IAC} 86 ; \mathrm{T}_{14}=\mathrm{IAC} 47+\mathrm{IAC} 62+\mathrm{IAC} 86$.

$\mathrm{O}$ delineamento experimental utilizado foi em blocos ao acaso, com três repetições, contendo oito plantas por parcela, sem bordaduras laterais; para a coleta de dados, toda a parcela foi considerada útil. Utilizou-se o teste de Duncan para comparação das médias.

Observaram-se as características: percentagem de frutos verdes, verdes cana, cerejas, passas, secos e chochos, anualmente por ocasião da colheita.

A percentagem de frutos chochos foi avaliada anualmente conforme técnica preconizada por Antunes Filho e Carvalho (1957), considerando-se uma amostra de frutos colocados em água. Os frutos "bóias" foram contados, determinando a percentagem de frutos flutuantes, chochos.

Contou-se no momento da colheita o número total de frutos de uma amostra de um litro de café colhido por parcela, separando os frutos nos seguintes estádios: verde, verde-cana, cereja, passa e seco .

\section{RESULTADOS E DISCUSSÕES}

\section{Percentagem de frutos chochos}

Para a percentagem de frutos chochos, não foram detectadas, mediante análise de variância, diferenças significativas entre os tratamentos durante 0 decorrer dos anos, conforme pode ser observado na Tabela 1. Isso significa que a percentagem de frutos chochos nos anos de 1996 a 1998 manteve sempre a mesma tendência entre os tratamentos, mostrando que há uma uniformidade muito grande entre as linhagens com relação a essa característica. Dias (2002) encontrou valores semelhantes para a percentagem de chochos quando caracterizou linhagens de Catuaí Vermelho e Catuaí Amarelo por meio de técnicas multivariadas. 
NOGUEIRA, A. M. et al.

TABELA 1 - Resumo da Análise de Variância, para a percentagem de frutos chochos e percentagem de frutos verdes nos anos de 1996 a 1998, das linhagens Catuaí Vermelho e Catuaí Amarelo plantadas isoladas e em diferentes combinações, em São Sebastião do Paraíso. UFLA, Lavras, 2003.

\begin{tabular}{lccc}
\hline & & \multicolumn{2}{c}{ Quadrado Médio } \\
\cline { 3 - 4 } \multicolumn{1}{c}{ FV } & GL & Chocho & Verde \\
\hline Bloco & 2 & 0,09 & 54,98 \\
Tratamento & 13 & 0,15 & 29,79 \\
Erro (a) & 26 & 0,16 & 31,27 \\
Ano & 2 & 0,03 & $893,96 * *$ \\
Erro (b) & 4 & 0,15 & 68,41 \\
Tratamento*Ano & 26 & 0,02 & 43,52 \\
Erro (c) & 52 & 0,07 & 32,03 \\
\hline CV (a) \% & & 54,08 & 90,79 \\
CV (b) \% & 53,07 & 134,30 \\
CV (c) \% & 34,93 & 91,89 \\
\hline
\end{tabular}

* Significativo a $1 \%$ de probabilidade

\section{Percentagem de frutos verdes}

Pela análise de variância apresentada na Tabela 1 , houve diferenças significativas entre os tratamentos com relação aos anos analisados. O efeito dos anos sobre a percentagem de frutos verdes foi destacado, mostrando que os anos de 1996, 1997 e 1998 foram os que apresentaram diferenças entre os tratamentos, como pode ser visto na Tabela 2. Nos anos de 1996 e 1997, as médias não diferiram estatisticamente, isto é a quantidade de frutos verdes em média foi igual, e diferindo no ano de 1998, em que a quantidade de frutos verdes foi menor conforme pode ser observado na Tabela 2. Essa ocorrência possivelmente pode ter sido influenciada devido ao fato de que no ano de 1998 os frutos foram colhidos mais tarde, mas ainda dentro do seu ciclo de maturação.

\section{Percentagem de frutos verde cana}

Com relação à percentagem de frutos verde-cana, estádio intermediário entre o verde e o cereja, a análise de variância (Tabela 3) revelou que houve interação significativa entre os anos e os tratamentos envolvidos. Com o desdobramento dessa interação, ficou evidenciado que a diferença ocorreu entre os tratamentos apenas no ano de 1998. A linhagem da cultivar Catuaí Vermelho IAC 81 (tratamento 2) não diferiu estatisticamente dos tratamentos 5 (IAC 44 + IAC 99); 11 (IAC 47 + IAC 62); 6 (IAC 81 + IAC 99); 9 (IAC 62); 13 (IAC 62 + IAC 86); 1 (IAC 44 + IAC 81); 4 (IAC 44) e 3 (IAC 99); porém produziu maior quantidade de frutos verdecana, e, ocorrendo a menor quantidade na combinação do tratamento 14 (IAC 47 + IAC 62 + IAC 86) com mistura na proporção de $33 \%$ de cada linhagem, como pode ser observado pela Tabela 4.
Após o desdobramento da interação tratamentos dentro de anos, procedeu-se à comparação das médias, utilizando o teste de Duncan a 5\% de probabilidade. Constatou-se que as linhagens IAC 44 de Catuaí Vermelho e a linhagem IAC 47 de Catuaí Amarelo tiveram comportamento semelhante nos anos de 1995, 1997 e 1998, com percentual mais elevado de frutos verdecana no ano de 1997. A combinação das linhagens de Catuaí Amarelo constantes no tratamento 14 (IAC 47 + IAC 62 + IAC 86), quando plantadas misturadas na proporção de $33 \%$ de plantas de cada linhagem, teve variação na percentagem de frutos verde cana, mostrando ser igual nos anos de 1995 e 1997 e diferente em 1998. Do mesmo modo, se apresenta a multilinha formada pelas linhagens do tratamento 12 (IAC $47+$ IAC 86) de Catuaí Amarelo, quando plantadas na proporção de $50 \%$ de plantas, conforme pode ser observado pela Tabela 5.

TABELA 2 - Médias dos anos 1996 a 1998 para a percentagem de frutos verdes, considerando as linhagens de Catuaí Vermelho e Catuaí Amarelo plantadas isoladas e em diferentes combinações, em São Sebastião do Paraíso. UFLA, Lavras, 2003.

\begin{tabular}{cc}
\hline Anos & Médias \\
\hline 1996 & $7,33 \mathrm{a}$ \\
1997 & $10,07 \mathrm{a}$ \\
1998 & $1,07 \mathrm{~b}$ \\
\hline
\end{tabular}

Médias seguidas de mesma letra não diferem estatisticamente entre si pelo Teste de Duncan a $5 \%$ de probabilidade. 
TABELA 3 - Resumo da Análise de Variância, considerando a percentagem de frutos verde-cana das linhagens de Catuaí Vermelho e Catuaí Amarelo plantadas isoladas e em diferentes combinações em São Sebastião do Paraíso. UFLA, Lavras, 2003.

\begin{tabular}{lcc}
\hline \multicolumn{1}{c}{ FV } & GL & QM \\
\hline Bloco & 2 & 0,08 \\
Tratamento & 13 & 0,08 \\
Erro 1 & 26 & 0,08 \\
Ano & 2 & 1,37 \\
Erro 2 & 4 & 0,36 \\
Tratamento*Ano & 26 & $0,15 *$ \\
Erro 3 & 52 & 0,07 \\
\hline CV (a) \% & & 41,39 \\
CV (b) \% & & 86,04 \\
CV (c) \% & & 38,35 \\
\hline
\end{tabular}

\section{* Significativo a $5 \%$ de probabilidade}

TABELA 4 - Médias das percentagens do desdobramento de tratamento dentro do ano de 1998, de frutos verde-cana, considerando as linhagens de Catuaí Vermelho e Catuaí Amarelo plantadas isoladas e em diferentes combinações em São Sebastião do Paraíso. UFLA, Lavras, 2003

\begin{tabular}{rlr}
\hline Número & \multicolumn{1}{c}{ Tratamentos } & Médias \\
\hline 2 & (IAC 81) & $0.92 \mathrm{a}$ \\
5 & (IAC 44 + IAC 99) & $0.86 \mathrm{ab}$ \\
11 & (IAC 47 + IAC 62) & $0.77 \mathrm{abc}$ \\
6 & (IAC 81 + IAC 99) & $0.77 \mathrm{abc}$ \\
9 & (IAC 62) & $0.60 \mathrm{abc}$ \\
13 & (IAC 62 + IAC 86) & $0.60 \mathrm{abc}$ \\
1 & (IAC 44 + IAC 81) & $0.52 \mathrm{abcd}$ \\
4 & (IAC 44) & $0.52 \mathrm{abcd}$ \\
3 & (IAC 99) & $0.52 \mathrm{abcd}$ \\
10 & (IAC 86) & 0.34 bcd \\
12 & (IAC 47 + IAC 86) & $0.25 \mathrm{~cd}$ \\
8 & (IAC 47) & $0.25 \mathrm{~cd}$ \\
7 & (IAC 44 + IAC 81 + IAC 99) & $0.25 \quad \mathrm{~cd}$ \\
14 & (IAC 47 + IAC 62 + IAC 86) & $0,01 \quad \mathrm{~d}$ \\
\hline
\end{tabular}

Médias seguidas de mesma letra não diferem entre si pelo teste de Duncan a 5\% de probabilidade.

Ciênc. agrotec., Lavras, v. 29, n. 1, p. 18-26, jan./fev. 2005 
TABELA 5 - Desdobramento dos anos dentro dos tratamentos, para a percentagem de frutos verde cana considerando as linhagens de Catuaí Vermelho e Catuaí Amarelo plantadas isoladas e em diferentes combinações em São Sebastião do Paraíso. UFLA, Lavras, 2003.

\begin{tabular}{ccccc}
\hline \multirow{2}{*}{ Anos } & \multicolumn{5}{c}{ Médias dos Tratamentos } \\
\cline { 2 - 5 } & (IAC 44) & (IAC 47) & (IAC 47 com IAC 86) & (IAC 47 com IAC 62 e IAC 86) \\
\hline 1997 & $1,14 \mathrm{a}$ & $1,10 \mathrm{a}$ & $1,04 \mathrm{a}$ & $1,22 \mathrm{a}$ \\
1995 & $0,56 \mathrm{~b}$ & $0,56 \mathrm{~b}$ & $0,68 \mathrm{ab}$ & $0,78 \mathrm{a}$ \\
1998 & $0,51 \mathrm{~b}$ & $0,26 \quad \mathrm{~b}$ & $0,26 \quad \mathrm{~b}$ & $0,00 \mathrm{~b}$ \\
\hline
\end{tabular}

Médias seguidas de mesma letra na coluna não diferem estatisticamente entre si pelo Teste de Duncan a $5 \%$ de probabilidade.

\section{Percentagem de frutos cereja}

Pela análise de variância (Tabela 6), verifica-se que para a percentagem de frutos no estádio cereja, houve diferença significativa dos anos de colheita e maturação dos frutos das linhagens componentes do experimento, assim como a interação dos tratamentos com os anos de colheita. Por ocasião dos desdobramentos, realizou-se a comparação das médias utilizando o teste de Duncan a $1 \%$ de probabilidade, constatando, dessa forma, que as linhagens, tanto de Catuaí Vermelho como as de Catuai Amarelo comportaram-se diferentemente no decorrer dos anos.

Ao efetuar o desdobramento dos tratamentos dentro dos anos, conforme observado na Tabela 7, ocorreram diferenças entre os tratamentos nos anos de 1996 e 1998.

No ano de 1996, os 13 (IAC 62 + IAC 86); 2 (IAC 81); 9 (IAC 62) e 4 (IAC 44 + IAC 81), destacaram-se, embora significativamente iguais aos tratamentos 6 (IAC 81 + IAC 99); 12 (IAC 47 + IAC 86); 7 (IAC 44 + IAC 81 + IAC 99); 8 (IAC 47); 5 (IAC44 + IAC99); 14 (IAC 47+ IAC 62 + IAC 86); 3 (IAC 99); 10 (IAC 86) e 11 (IAC 47 + IAC 62) com maior percentual de frutos no estádio cereja. A menor percentagem de frutos cereja foi encontrada no tratamento 1 ( IAC 44). Dentre as combinações as que se destacaram foram as compostas pelas combinações das linhagens pertencentes ao tratamento 13 (IAC 62 + IAC 86) de Catuaí Amarelo e tratamento 4 (IAC 44 + IAC 81) de Catuaí Vermelho, com 50\% de cada linhagem compondo a mistura. Nas linhagens cultivadas isoladamente, os maiores percentuais de frutos cereja foram encontrados nas linhagens IAC 44 e IAC 81, ambas de Catuaí Vermelho.
No ano de 1998, a linhagem IAC 44 (tratamento 1) obteve bom desempenho, com a maior percentagem de frutos cereja. A menor percentagem foi encontrada na combinação das linhagens do tratamento 12 (IAC 47 + IAC 86) de Catuaí Amarelo.

As linhagens, tanto das cultivares Catuaí Vermelho quanto as de Catuaí Amarelo, tiveram percentagem de frutos cereja bastante diferenciadas; entretanto a combinação das linhagens do tratamento 14 (IAC $47+$ IAC 62 + IAC 86) de Catuaí Amarelo foi a que mostrou ser mais estável para essa característica com o decorrer dos anos.

Pimenta (1995) avaliou a composição química e atividades de algumas enzimas em cafés arábica nos estádios de maturação verde, verde-cana, cereja e seco na planta e observou que os cafés no estádio de maturação cereja apresentaram melhores características de qualidade, ou seja maiores teores de açúcares, menores teores de compostos fenólicos, e consequentemente menor adstringência e menores índices de lixiviação de potássio, indicando maior integridade da membrana.

Bartholo e Guimarães (1997), citados por Severino (2000), observaram que para se obter qualidade de bebida satisfatória, é preciso que $80 \%$ dos frutos estejam no estádio cereja, no momento da colheita.

\section{Percentagem de frutos passa}

Para a característica percentagem de frutos no estádio passa, existe diferença significativa para os tratamentos e os anos de colheita e não existe relação de dependência para a interação tratamentos e anos conforme pode ser observado pela análise de variância (Tabela 8). 
TABELA 6 - Resumo da Análise de Variância para a percentagem de frutos cereja e percentagem de frutos passa nos anos de 1995 a 1999, das linhagens de Catuaí Vermelho e Catuaí Amarelo, plantadas isoladas e em diferentes combinações em São Sebastião do Paraíso. UFLA, Lavras, 2003.

\begin{tabular}{lrcc}
\hline & & & QM \\
\cline { 3 - 4 } & GL & Cereja & Passa \\
\hline Bloco & 2 & 219,09 & 1,39 \\
Tratamento & 13 & 95,08 & $86,44 * *$ \\
Erro(a) & 26 & 56,89 & 28,52 \\
Ano & 4 & $24233,20^{* *}$ & $5044,95^{* *}$ \\
Erro(b) & 8 & 239,54 & 92,67 \\
Tratamento*Ano & 52 & $138,27^{* *}$ & 55,05 \\
Erro(c) & 104 & 73,99 & 43,30 \\
\hline CV (a) \% & & 14,74 & 24,02 \\
CV (b) \% & & 30,24 & 43,30 \\
CV (c)\% & & 16,81 & 29,60 \\
\hline
\end{tabular}

** Significativo a $1 \%$ de probabilidade

TABELA 7 - Desdobramento do efeito de tratamento dentro dos anos, de 1996 e 1998 para a percentagem de frutos cereja, considerando as linhagens de Catuaí Vermelho e Catuaí Amarelo plantadas isoladas e em diferentes combinações em São Sebastião do Paraíso. UFLA, Lavras 2003.

\begin{tabular}{rlcc}
\hline $\mathbf{N}^{\mathbf{0}}$ & \multicolumn{2}{c}{ Tratamentos } & Anos \\
\cline { 3 - 4 } & & $\mathbf{1 9 9 6}$ & $\mathbf{1 9 9 8}$ \\
\hline 13 & (IAC 62 + IAC 86 & $63,33 \mathrm{a}$ & $41,67 \mathrm{abcde}$ \\
2 & (IAC 81) & $60,00 \mathrm{a}$ & $48,33 \mathrm{abc}$ \\
9 & (IAC 62) & $58,33 \mathrm{a}$ & $46,67 \mathrm{abcd}$ \\
4 & (IAC 44+ IAC 81) & $50,00 \mathrm{abc}$ \\
6 & (IAC 81 + IAC 99) & $56,67 \mathrm{ab}$ & $45,00 \mathrm{abcd}$ \\
12 & (IAC 47 + IAC 86) & $56,67 \mathrm{ab}$ & $21,67 \quad$ e \\
7 & (IAC 44 + IAC 81 + IAC 99) & $53,33 \mathrm{ab}$ & 36,67 bcde \\
8 & (IAC 47) & $51,67 \mathrm{ab}$ & 35,00 bcde \\
5 & (IAC44 + IAC99) & $48,33 \mathrm{ab}$ & 35,00 bcde \\
14 & (IAC 47+ IAC 62 + IAC 86) & $46,67 \mathrm{ab}$ & 40,00 abcde \\
3 & (IAC 99) & $45,00 \mathrm{ab}$ & $30,00 \quad$ cde \\
10 & (IAC 86) & $45,00 \mathrm{ab}$ & 26,67 \\
11 & (IAC 47 + IAC 62) & $43,33 \mathrm{ab}$ & 51,67 abc \\
1 & (IAC 44) & $36,67 \mathrm{~b}$ & $60,00 \mathrm{a}$ \\
\hline
\end{tabular}

Médias seguidas de mesma letra nas colunas não diferem estatisticamente entre si pelo teste de Duncan a 1\% de probabilidade. 
TABELA 8 - Médias dos anos, para a percentagem de frutos passa considerando as linhagens de Catuaí Vermelho e Catuaí Amarelo plantadas isoladas e em diferentes combinações em São Sebastião do Paraíso. UFLA, Lavras, 2003.

\begin{tabular}{ll}
\hline Anos & Médias \\
\hline 1995 & $4,76 \quad \mathrm{c}$ \\
1996 & $21,36 \mathrm{~b}$ \\
1997 & $22,07 \mathrm{~b}$ \\
1998 & $32,72 \mathrm{a}$ \\
1999 & $30,24 \mathrm{a}$ \\
\hline
\end{tabular}

Médias seguidas de mesma letra não diferem estatisticamente entre si pelo Teste de Duncan a 5\% de probabilidade.

Na Tabela 9, verificam-se as diferenças das médias representativas dos diversos tratamentos. Quando realizado o desdobramento para os tratamentos, a combinação das linhagens do tratamento 13 (IAC 62 + IAC 86) de Catuaí Amarelo foi a que menor percentagem de frutos passa apresentou, porém, sendo estatisticamente igual aos tratamentos 12,5 , $14,6,11,4,9,1$ e 2 .

Entretanto, a linhagem de Catuaí Vermelho IAC 99 (tratamento 3), a combinação do tratamento 7 (IAC 44 + IAC 81 + IAC 99) também de Catuaí Vermelho e a linhagem de Catuaí Amarelo IAC 86 (tratamento 10), foram as de maior percentagem de frutos-passa, conforme observado na Tabela 9 abaixo.

\section{Percentagem de frutos secos}

Obeserva-se pela análise de variância (Tabela 10) que houve significância para a interação tratamento versus ano, e este efeito mostra que houve resposta diferenciada das linhagens em relação aos anos, para a percentagem de frutos no estádio de seco.

Pelos resultados obtidos, mostrados na Tabela 11, observa-se que as linhagens estão distribuídas em dois grupamentos e indistintamente se isoladas ou em combinação, entre as linhagens de Catuaí Vermelho e Catuaí Amarelo. A maior percentagem de frutos secos ocorreu na combinação das linhagens IAC 44 + IAC 99 (tratamentos 5), IAC 81 + IAC 99 (tratamento 6), IAC 62 + IAC 86 (tratamento13) e IAC 47 + IAC 62 (tratamento11).

Com o desdobramento da interação ano dentro de tratamento, ficou evidente que a combinação das linhagens de Catuaí Vermelho dos tratamentos 5 (IAC 44 + IAC 99); (IAC 81 + IAC 99) e 13 (IAC 62 + IAC 86), sendo esse último tratamento composto por linhagens de Catuai Amarelo foram as que menor percentagem de frutos secos tiveram nos anos de 1996, 1998 e 1999, e maior percentagem no ano de 1997, conforme Tabela 12.

Por ocasião do desdobramento entre os anos, constatou-se que o ano de 1995 foi melhor em relação aos demais anos, com menor percentagem, para a característica de frutos no estádio de passa, conforme observado na Tabela 9.

TABELA 9 - Médias de tratamento para a percentagem de frutos passa, considerando as linhagens de Catuaí Vermelho e Catuaí Amarelo, plantadas isoladas e em diferentes combinações em São Sebastião do Paraíso. UFLA, Lavras, 2003.

\begin{tabular}{clc}
\hline $\mathbf{N}^{\mathbf{0}}$ & \multicolumn{1}{c}{ Tratamentos } & Médias \\
\hline 13 & (IAC62 + IAC86) & $17,67 \mathrm{c}$ \\
2 & (IAC 81) & $18,67 \mathrm{bc}$ \\
1 & (IAC 44) & $20,47 \mathrm{abc}$ \\
9 & (IAC 62) & $21,33 \mathrm{abc}$ \\
4 & (IAC 44 + IAC 81) & $21,33 \mathrm{abc}$ \\
11 & (IAC 47 + IAC 62) & $21,53 \mathrm{abc}$ \\
6 & (IAC 81 + IAC 99 & $21,60 \mathrm{abc}$ \\
14 & (IAC 47 + IAC 62 + IAC 86) & $21,73 \mathrm{abc}$ \\
5 & (IAC 44 + IAC 99) & $23,07 \mathrm{abc}$ \\
12 & (IAC 47 + IAC 86) & $23,67 \mathrm{abc}$ \\
8 & (IAC 47) & $24,20 \mathrm{ab}$ \\
10 & (IAC 86) & $25,27 \mathrm{a}$ \\
7 & (IAC 44 + IAC 81 + IAC 99) & $25,33 \mathrm{a}$ \\
3 & (IAC 99) & $25,40 \mathrm{a}$ \\
\hline
\end{tabular}

Médias seguidas de mesma letra não diferem estatisticamente entre si, pelo teste de Duncan a 1\% de probabilidade.

Ciênc. agrotec., Lavras, v. 29, n. 1, p. 18-26, jan./fev. 2005 
TABELA 10 - Resumo da Análise de Variância para a percentagem de frutos secos nos anos de 1996 a 1999 , das linhagens de Catuaí Vermelho e Catuaí Amarelo plantadas isoladas e em diferentes combinações em São Sebastião do Paraíso. UFLA, Lavras, 2003.

\begin{tabular}{lrc}
\hline \multicolumn{1}{c}{ F.V. } & GL & QM \\
\hline Bloco & 2 & 411,61 \\
Tratamento & 13 & 90,92 \\
Erro(a) & 26 & 116,38 \\
Ano & 3 & 1678,26 \\
Erro(b) & 6 & 914,03 \\
Tratamento*Ano & 39 & $273,22 *$ \\
Erro(c) & 78 & 171,75 \\
\hline CV (a) & & 44,11 \\
CV (b) & & 123,61 \\
CV (c) & & 53,58 \\
\hline
\end{tabular}

* Significativo a $5 \%$ de probabilidade.

TABELA 11 - Médias dos tratamentos dentro do ano de 1997 para a percentagem de frutos secos, considerando as linhagens Catuaí Vermelho e Catuaí Amarelo, plantadas isoladas e em diferentes combinações em São Sebastião do Paraíso. UFLA, Lavras, 2003.

\begin{tabular}{rll}
\hline $\mathbf{N}^{\mathbf{0}}$ & \multicolumn{1}{c}{ Tratamentos } & Médias \\
\hline 14 & $($ IAC 47 + IAC 62 + IAC 86) & $15,00 \mathrm{ab}$ \\
1 & $($ IAC 44) & $18,33 \mathrm{ab}$ \\
12 & $($ IAC 47 + IAC 86) & $21,67 \mathrm{ab}$ \\
8 & (IAC 47) & $21,67 \mathrm{ab}$ \\
3 & (IAC 99) & $26,67 \mathrm{ab}$ \\
4 & (IAC 44 + IAC 81) & $26,67 \mathrm{ab}$ \\
7 & (IAC 44 + IAC 81 + IAC 99) & $28,33 \mathrm{ab}$ \\
10 & (IAC 86) & $35,00 \mathrm{ab}$ \\
9 & (IAC 62) & $41,00 \mathrm{ab}$ \\
2 & (IAC 81) & $41,67 \mathrm{ab}$ \\
11 & (IAC 47 + IAC 62) & $46,00 \mathrm{a}$ \\
13 & (IAC 62 + IAC 86) & $49,00 \mathrm{a}$ \\
6 & (IAC 81 + IAC 99) & $49,33 \mathrm{a}$ \\
5 & (IAC 44 + IAC 99) & $49,33 \mathrm{a}$ \\
\hline
\end{tabular}

Médias seguidas de mesma letra não diferem entre si pelo Teste de Duncan a 1\% de probabilidade.

Ciênc. agrotec., Lavras, v. 29, n. 1, p. 18-26, jan./fev. 2005 
TABELA 12 - Médias dos anos de 1996 a 1999 para os tratamentos para a percentagem de frutos secos considerando as linhagens de Catuaí Vermelho e Catuaí Amarelo plantadas isoladas e em diferentes combinações em São Sebastião do Paraíso. UFLA, Lavras, 2003.

\begin{tabular}{|c|c|c|c|}
\hline \multirow[b]{2}{*}{ Anos } & \multicolumn{3}{|c|}{ Tratamentos } \\
\hline & (IAC 44+ IAC 99) & (IAC 81 + IAC 99) & $($ IAC $62+$ IAC 86 ) \\
\hline 1996 & $18,33 \mathrm{~b}$ & $11,67 \quad b$ & $11,67 \quad b$ \\
\hline 1997 & 49,33 a & 49,33 a & 49,00 a \\
\hline 1998 & $16,67 \mathrm{~b}$ & $15,00 \mathrm{~b}$ & $21,67 \quad b$ \\
\hline 1999 & $20,00 \mathrm{~b}$ & $25,00 \mathrm{a} b$ & 28,33 a b \\
\hline
\end{tabular}

Médias seguidas de mesma letra nas colunas não diferem estatisticamente entre si pelo Teste de Duncan a 5\% de probabilidade.

\section{CONCLUSÃO}

Pelos resultados obtidos, em que foram evidenciadas diferenças significativas dos percentuais entre os diferentes estádios de maturação dos frutos, independente de estar a linhagem individualizada ou em mistura nas diferentes proporções, pode-se concluir que a formação de multilinhas não exerceu influência sobre as características analisadas.

As variações podem ser atribuídas às diferentes épocas de florações ocorridas, em maior ou menor intensidade, nos tratamentos que influenciam os estádios de maturação.

Notou-se, também que não houve melhoria na uniformidade de maturação, permanecendo a característica para as cultivares Catuaí Vermelho e Catuaí Amarelo.

As considerações decorrentes deste trabalho são pertinentes à região de São Sebastião do Paraíso; portanto, extrapolações para outros locais devem ser tomadas com reservas.

\section{REFERÊNCIAS BIBLIOGRÁFICAS}

ANTUNES FILHO, H.; CARVALHO, A. Melhoramento do cafeeiro: XI. análise da produção e de progênies de híbridos de Bourbon Vermelho. Bragantia, Campinas, v. 16, n. 13, p. 175-195, nov. 1957.

BARTHOLO, G. F.; GUIMARÃES, P. T. G. Cuidados na colheita e preparo do café. Informe Agropecuário, Belo Horizonte, v. 18, n. 187, p. 33-42, 1997.

CANNELL, M. G. R. Seasonal patterns of growth and developmaent of arabica coffee in Kenya: IV. effects of seasonal differences in rainfall on bean size. Kenya Coffee, Nairobi, v. 36, n. 2, p. 176-180, 1971.

CARVALHO, V. D. de. Qualidade do café. Lavras: UFLA, 1998. $53 \mathrm{p}$.

CARVALHO, V. D. de; CHALFOUN, S. M. Colheita e preparo de café. Lavras: UFLA/FAEPE, 2000. 36 p.

DIAS, F. P. Caracterização de progênies de cafeeiro ( Coffea arabica L.) por meio e tácnicas multivariadas. 2002. 62 p. Dissertação (Mestrado em Fitotecnia) Universidade Federal de Lavras, Lavras, 2002.

PIMENTA, C. J. Qualidade do Café (Coffea arabica L.) originado de diferentes frutos colhidos em quatro estádio de maturação. 1995. 94 f. Dissertação (Mestrado em Ciência dos Alimentos) - Universidade Federal de Lavras, Lavras, 1995.

SEVERINO, L. S. Caracterização de progênies Catimor e avaliação de descritores em (Coffea arabica L.). 2000. 85 f. Dissertação (Mestrado em Fitotecnia) - Universidade Federal de Viçosa, Viçosa, 2000.

SONDAHL, M. R.; SHARP, W. R. Research in Coffea spp. and aplications of tissue culture methods. In: SHARP, W. R. et al. (Eds.). Plant cell and tissue culture principles and applications. Columbus: Ohio State University, 1979.

WORMER, T. M. The growth of the coffe berry. Annals of Botany, London, v. 28, n. 1, p. 47-55, Jan. 1964. 
